\title{
Increased Therapeutic Response
}

National Cancer Institute

\section{Source}

National Cancer Institute. Increased Therapeutic Response. NCI Thesaurus. Code C50611.

An increase in the desirable and beneficial effects resulting from a medical treatment. 